\title{
Severe and Unusual domestic Violence; A Case Report and Review of Literature
}

\author{
Zarenezhad $\mathrm{M}^{1}$, Valee $\mathrm{M}^{1}$, Gholamzadeh $\mathrm{S}^{*}$, Malekpour $\mathrm{A}^{1}$ and Keshavarz $\mathrm{P}^{2}$ \\ ${ }^{1}$ Legal Medicine Research Center, Legal Medicine Organization of Iran, Tehran, Iran \\ ${ }^{2}$ Shiraz University of Medical Sciences,Shiraz,Iran
}

${ }^{*}$ Corresponding author: Gholamzadeh S, Legal Medicine Research Center, Legal Medicine Organization of Iran, Tehran, Iran, Tel: +98713-6324100, E-mail: saeedghmail@yahoo.com

Citation: Zarenezhad M, Valee M, Gholamzadeh S, Malekpour A, Keshavarz P (2016) Severe and Unusual domestic Violence; A Case Report and Review of Literature. J Case Rep Stud 4(6): 601. doi: 10.15744/23489820.4.601

Received Date: August 07, 2016 Accepted Date: December 27, 2016 Published Date: December 29, 2016

\begin{abstract}
Violence against women is one of the most systematic and prevalent human rights abuses in the world. Here, we aim to demonstrate a case of sever domestic violence from rural area suffering severe injuries. A 24 years old woman that has been under the violence of her worker husband aged 35 years old without any previous history of referring to legal medicine organization. She suffered broken nose, several body bruise, sever bleeding in conjunctiva, pulled nail injuries and bleeding as well as several parallel scrapes of self-mutilations on different parts of the body. Severe injuries were also observed in perineal and genital area; her vaginal, perineal and major labia were sutured by her husband resulted in severe infection and putrefactive smell. Finally, she gave up her compliance without any reason and outcome perhaps because of shame, fear and social barriers. Educational psychological programs are needed to prevent such violent events even in families with high difference of the parents' age.
\end{abstract}

Keywords: Case Report; Domestic Violence; Sutured Perineal Area

\section{Introduction}

Violence against women is one of the most prevalent human rights abuses in the world which harms families and communities [1]. Violence against women affects their quality of life, autonomy, productivity, physical and mental well-being [2]. The World Health Organization (WHO) indicated that worldwide domestic violence against women was ranged 15\% in Japan to the highest level $71 \%$ in Ethiopia [3]. Domestic violence is common in both urban and rural families and about $81 \%$ of women believed that a husband is justified in beating his wife [4,5]. Howard et al. mentioned that there is a high prevalence of domestic violence in individuals with psychiatric problems [5]. Women suffer physical, emotional, sexual and economic violence by their husbands and it is usually protected and covered by fear, shame, family secrecy, cultural norms, community's reluctance on domestic affair and social stigma made the women remain silent $[2,3,6,7]$. In this case report study, we aim to demonstrate a case of sever domestic violence from rural area and ethnic family from Middle East countries suffering severe injuries. In this area, people have severe familial and ethnic behaviors and bigotry senses are considered as a main parameter in cultural structure of family.

\section{Case Report}

A 24 years old woman referred to Legal Medicine Organization of Fars province for compliance about domestic violence. Her husband was a simple worker and had the age of 35 years old and was 11 years more old than the wife. She has been married for 4 years and claimed that has been under the violence of her husband since their wedding. She had education at the level of high school and low socioeconomic status. She mentioned that she had not previous history of referring to legal medicine organization and even she had not expressed the problems to her parents and relatives. In general examination, she seemed stupefied and mute with broken nose, several body bruise, sever bleeding in conjunctiva, pulled nail injuries and nail bleeding. Several self-mutilations were also observed in different parts of the body looked like parallel scrapes and rat tail scratches. Sever injuries were also observed in perineal and genital area; her vaginal and perineal area as well as major labia were sutured by her husband resulted in severe infection and putrefactive smell (Figure 1). It should be mentioned that the victim has not reported the injuries of her perineal area herself and it was discovered from bad putrefactive smell. She was referred to hospital for curative treatments and also for psychological investigations. 


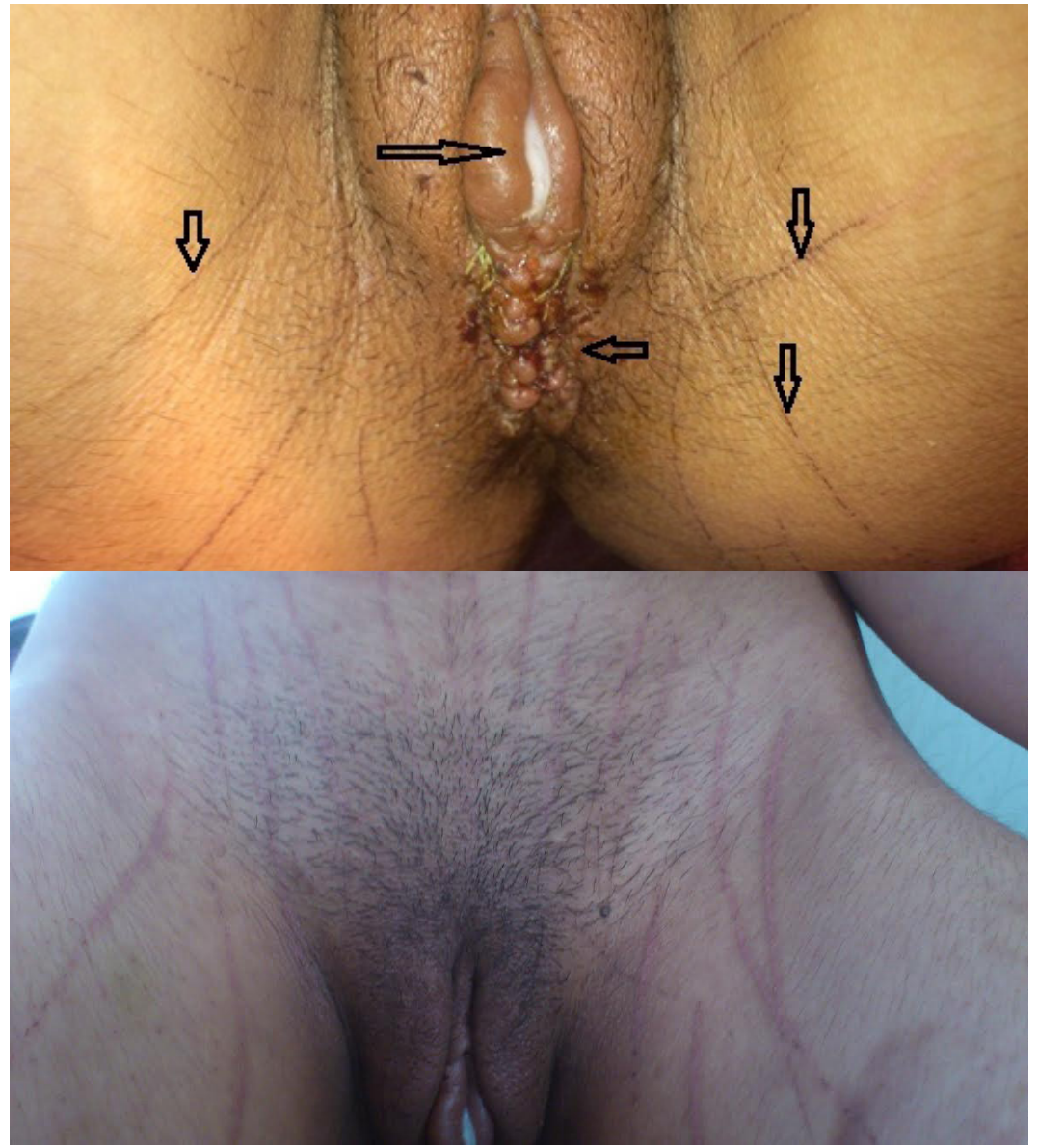

Figure 1: Female Genital Mutilation (Horizontal arrows: Stitching perineal area, Major labia as well as infectious discharges, Vertical arrows: scratches indicating self-mutilation)

\section{Discussion}

Domestic violence is described as the power, misused by one adult in a relationship, to control another. Most commonly the victims are women and the perpetrators are their husbands [8]. Violence against women is a major health and human rights [9] that it has reached epidemic proportions in many societies [5]. Violence toward women is both a cause and a consequence of gender inequality, and thus creates a significant obstacle for achieving the Millennium Development Goals [3,10]. The consequences of domestic violence are extensive and range from the direct physical and mental harm for women and loss of quality of life to economic losses at the community and national level. Physical violence is prevalent in both developed and developing countries having poor health, depressive symptoms, substance abuse problems, and developing chronic diseases and mental illnesses but its more prevalent in societies with low socioeconomic properties [11-13]. Violence against women also affects quality of life and physical and mental health [14]. This study showed high levels of domestic violence against woman with low socioeconomic status. Although the consequences of domestic violence are well documented, there is less evidence and insight about mental and psychological basis in such events that could help reduce domestic violence. In our case, it seems that quality of life and physical and mental health is not such important for individuals with low socioeconomic levels. For dogmatic violent men, bigotry sense causes to do such severe violent actions and even homicide may occur [15] and on the other hand fear, shame and traditional thoughts leads to women avoid expression of such problems to parents, relatives or to complain and get their rights. There is no literature nor report about closing the vaginal area with suturing the perineal area and major labia by husband so far; based of the findings it seems that this action was performed to punish the wife because of her treats. One of interesting aspects of this event is that the victim had not any compliance on suturing her perineal area during the interview and we found it from its bad smell. In this case, in addition to mental and physical violent actions from husband, symptoms of self-mutilation was also observed, perhaps because of increasing the criminal aspect of the event presenting in rat tail scratches. Such injuries are usually considered as selfmutilation [16,17]. Considering high difference of the age between wife and her husband, we can conclude that this situation has led to miss-understanding of other and violent reactions. On the other hand, in rural areas, pudency is highly considered by people especially men and severe violent reactions will occur in response to suspicious sexual events. On the other hand, the women avoid to present such events and any complaint about that because of their treats shames and cultural bands. We recommend creating awareness and educational programs especially in areas with low socioeconomic status to prevent and decrease the domestic violence and to avoid wife beating and irreversible consequences. 


\section{Acknowledgment}

The authors thank personnel of Fars Legal Medicine Organization for interview with the patient and filling the questionnaire.

\section{References}

1. Gracia E, Tomás JM (2014) Correlates of victim-blaming attitudes regarding partner violence against women among the Spanish general population. Violence Against Women 20: 26-41.

2. Devries KM, Mak JY, García-Moreno C, Petzold M, Child JC, et al. (2013) The global prevalence of intimate partner violence against women. Science 340: 1527-8.

3. Pallitto CC, García-Moreno C, Jansen HA, Heise L, Ellsberg M, et al. (2013) Intimate partner violence, abortion, and unintended pregnancy: results from the WHO Multi-country Study on Women's Health and Domestic Violence. Int J Gynaecol Obstet 120: 3-9.

4. Dahlstedt JK (2013) Notification and Risk Management for Victims of Domestic Violence. Wis. JL Gender, \& Soc'y $28: 1$.

5. Alhabib S, Nur U, Jones R (2010) Domestic violence against women: Systematic review of prevalence studies. J Famil Violence 25: $369-82$.

6. Kalra N, Garcia-Moreno C (2015) Training Health Care Providers to Respond to Intimate Partner Violence Against Women: Title for a Systematic Review.

7. Dutton DG (1995) The Domestic Assault of Women: Psychological and Criminal Justice Perspectives, UBC press.

8. Rennison CM, Welchans S (2000) Intimate partner violence. Violence against women 1993: 98.

9. Kumar S (2015) Married women's view about domestic violence: A qualitative study of Kandaghat block of district Solan. IJAR 1: 1-7.

10. World Health Organization (2005) WHO multi-country study on women's health and domestic violence against women: report of initial results on prevalence, health outcomes and women's responses.

11. Dillon G, Hussain R, Loxton D, Rahman S (2013) Mental and physical health and intimate partner violence against women: a review of the literature. Int J Family Med 10.1155/2013/313909.

12. Lacey KK, McPherson MD, Samuel PS, Powell Sears K, Head D (2013) The impact of different types of intimate partner violence on the mental and physical health of women in different ethnic groups. J Interpers Violence 28: 359-85.

13. Trevillion K, Oram S, Feder G, Howard LM (2012) Experiences of domestic violence and mental disorders: a systematic review and meta-analysis. PLoS One 7: e51740.

14. Tinker A, Finn K, Epp J (2000) Improving Women's Health: Issues and Interventions. Health, Nutrition and Population. The World Bank.

15. Stone MH (2015) Mass murder, mental illness, and men. Violence and Gender 2: 51-86.

16. Hedjazi A, Hoseinzadeh A, Zarenezhad M, Hassanzadeh R, Mahmoudi D, et al. (2013) A report of five cases of self-mutilation for the purpose of insurance fraud. J Forensic Leg Med 20: 640-3.

17. Zanarini MC, Laudate CS, Frankenburg FR, Wedig MM, Fitzmaurice G (2013) Reasons for self-mutilation reported by borderline patients over 16 years of prospective follow-up. J Pers Disord 27: 783-94. 